\title{
Does Facebook Matter in Egyptian Graduate Environment? A Marketing Perspective
}

\author{
Ahmad Y. Ebeid \\ Associate professor, Faculty of Commerce, Mansoura University, Mansoura, Egypt \\ E-mail: a_yehia75@mans.edu.eg
}

Received: March 31, $2012 \quad$ Accepted: April 16, $2012 \quad$ Published: June 1, 2012

doi:10.5539/ijms.v4n3p153 URL: http://dx.doi.org/10.5539/ijms.v4n3p153

\begin{abstract}
The current study is exploratory, and it aims at uncovering the potential role of Facebook in Egyptian university environment. The research based on 127 questionnaires. It was found that; $42 \%$ of the respondents use Facebook for educational purpose; around $85 \%$ use Facebook to be in touch with their teachers; more than $75 \%$ use Facebook to contact the faculty administration; more than $70 \%$ of students are convinced that they have added value when using Facebook in the educational context. These results would support the notion of using Facebook as an untraditional, cheap, interactive means to enhance the quality of the educational service that provided by the college (producer) and received by the student (customer). Implications were presented and suggestion for further studies was highlighted.
\end{abstract}

Keywords: Facebook, Educational service quality, Egyptian revolution

\section{Introduction}

Social Networking Sites (SNSs) are considered as phenomenon. They have been changing the communication world, by creating virtual communities. SNSs could be defined as "virtual communities which allow people to connect and interact with each other on a particular subject or just hand out together online" (Dogruer Menevis, \& Eyyam, 2011, p. 2642). The current researcher sees social network as an untraditional communication means, which enhances the connection between people, by using advanced options, enabling to create online-based communities.

Users can get many options when using a social network; as sharing photos with others, exchanging information, etc. (Grosseck, Bran, \&Tiru, 2011; Dogruer, et al., 2011).

As Students nowadays need to have the ability to process information (Uzunboylu, Bicen, \& Cavus, 2011), current researcher argues that there is a necessity to study the range of using (SNSs) to enhance such ability, which in return supports the learning process. It was found that "mentoring theory may provide a theoretical basis for defining an instructional role for SNSs" (Roblyer, McDaniel, Webb, Herman, \& Witty, 2010, p.137), also, it was stated that "social media in higher education has been proven to enhance the study experience of learners by providing student support, including e-mentoring" (Dabner, 2012, p.70).

Adaptability deemed as a highly required feature of a university (Craciun, 2010). Accordingly, colleges need to adapt themselves with the changes that occur in educational environment. In other words, colleges need to respond -appropriately - to the customer-driven changes. Regarding the study concern, researcher argues that there is a necessity to replace the traditional means of communication with the most common ones that the students use. Thus, (SNSs) would help in this context.

\section{Why Facebook, Specifically?}

Facebook is "a social network that provides an interface for people to communicate with friends, family, and coworkers" (Pilgrim \& Bledsoe, 2011, p. 38).

Current researcher chose Facebook, specifically, as an example of (SNSs), based on its popularity (Bicen \& Cavus, 2011; Pilgrim \& Bledsoe, 2011; Smith\& Kidder, 2010; Roblyer et al., 2010); it was ranked first among (SNSs) (Dogruer, et al., 2011), and is seen as the most common platform for online social networks among university students (Kabilan, Ahmad, \& Abidin, 2010). The number of Facebook users exceeds 500 million (Grosseck et al. 2011; Pilgrim \& Bledsoe, 2011), thus it is considered as the third largest country in terms of 
population (Attia, Aziz, Friedman, \& Elhusseiny, 2011). Current researcher considers flexibility that Facebook has as one of the reasons that resulted in such popularity; it is a multilingual-online social network, and it can be accessed also through mobile devices as well (more than 65 million users per day) (Kabilan, et al., 2010).

In addition, there are many contextual justifications that led researcher to choose Facebook; 1-The first issue of Facebook was in 2004 (Hum, Chamberlin, Hambright, Portwood, Schat, \& Bevan, 2011) to socialize college students in the United States (Grosseck, et al., 2011). It was launched in February for Harvard students, by Mark Zuckerberg, Dustin Moskovitz, and Chris Hughes (Dogruer, et al., 2011, p. 2642), and extended to British universities in October 2005 (West, Lewis, \& Currie, 2000); 2- The number of Facebook users in Egypt in 2009 was 800,000 , it was ranked as the third most visited Website in Egypt, and it played a great role in the Egyptian revolution in 2011 (Attia, et al., 2011); 3- "The popularity of Facebook with college aged students" (Dabner, 2012, p. 71); 4- As "learning emerges from our own actions in relation to those of others" (Korthagen, 2010, p. 99), it's a great role that expected from Facebook in the university environment, that based on its unique features which enable Facebook to offer constructive educational experiences (Kabilan, et al., 2010); 5- Educators have used Facebook to be in touch with students and parents (Pilgrim \& Bledsoe, 2011). 6- The current researcher has been engaged with a number of graduate students in an experiment, in terms of using Facebook for educational purposes. Researcher -as a teacher- has joined a Facebook group (WWW.facebook.com/group/pre.ma2012/), in the fall semester of the Academic year 2011/2012 which was launched for educational purposes. Accordingly, the researcher considers Facebook the most relevant social network for the current study.

Currently, universities are encountered with the difficulty of supporting and maintaining their own competitive advantage in the educational markets (Al-Alak \& Alnaser, 2012). In this context, the college is to be looked at as a service provider, and the student is considered as a customer. As such institute produces services, it should consider quality (Lapierre, Filiatrault \& Perrien, 1996), "that has become more demanding" (Dragut, 2011, p. 3368). This perspective would get colleges aware of figuring out the quality dimensions of educational service to get customers (learners) satisfied. The issue of educational service quality is considered so essential, because of its relation to the labor market that has narrowed a lot lately (Dragut, 2011). There are many dimensions to evaluate the educational service quality. The ones which could be the most related to the present study concern are: "quality and quantity of educational facilities, quality and number of modern means of education, quality of information services, and especially the quality of teacher-learner relations" (Cîrneanu, Chiriță \& Cîrneanu, 2009, p.11).

Since searching for untraditional ways to attract, encourage and maintain stronger relationships between college and its students is essential in terms of having a competitive edge in the future (Al-Alak \& Alnaser, 2012), current researcher argues that, Facebook would be operationlized to support the college efforts regarding enhancing such relationships.

The significance of the study that addresses the Facebook usability in terms of Egyptian educational context would be increased if it is combined with the issue of academic accreditation. National Authority for Quality Assurance \& Accreditation of Education-Egypt (NAQAAE) devotes the necessity of enhancing the connection between the student and the educational institution, and considers this issue as a requirement for institutional accreditation. Accreditation, in return, could be seen as a competitive advantage, that a college would use to enhance its own image.

The aim of the study is to explore the potential role of Facebook in Egyptian university environment, based on a great success that social networks accomplished in terms of operationalizing the Web 2.0 technologies in the social context (Kabilan, et al., 2010); relying on the studies that referred to Facebook as it 'can be useful' in the academic setting (Bicen \& Cavus, 2011; Grosseck et al., 2011; Roblyer et al., 2010).

\section{Research Question}

The researcher states a set of Research Questions (RQs) in terms of fulfilling the aim of the study, as follows:

Q1: What is the intensity of using Facebook among graduate students?

Q2: For what purpose/purposes, graduate students use Facebook?

Q3: Do graduate students get added value in terms of using Facebook in terms of educational context?

Q4: Are graduate students satisfied with the current level of interaction between them and their teachers, colleagues, and administration?

Q5: Do students' responses about the different aspects of using Facebook in the educational context (section2 of the questionnaire) vary according to the gender and age? 


\section{Method}

The current study is exploratory. To collect the primary data, participants were asked different questions (Note 1). Such questions would be categorized into three sections; the first (Q1-Q4) is introductory; addresses whether the participant has Facebook account or not, the frequency of using Facebook, the purpose/purposes for which he/she uses Facebook, the language in which participants use Facebook, (Q1-Q4) are multiple choice questions. The second section (Q5-Q16) reflects different aspects in which a student uses Facebook in the educational environment; 5-point Liker scale was used to range the responses of such questions; where $5=$ completely agree and 1= not at all agree. The third section $(\mathrm{Q} 17$ \& Q18) contains a set of personal data (gender, age). All of the questions were presented in Arabic Language.

Unlike studies in which undergraduate were of concern (Smock, Ellison, Lampe, \& Wohnb, 2011; Bicen \& Cavus, 2011), current study targeted graduate students enrolled in the preparatory one-year program for Master degree (academic year 2011-2012), in the Faculty of Commerce, Mansoura University, Egypt. The total number of students who attended the first-day exam - of fall semester - was 265 students. The number of questionnaires collected for our current study was 127 . This percentage represents approximately $48 \%$ of the study population. Researcher chose this graduate students' population because of the nature of their study that makes them in need to share their assignments, data, tables, figures, etc., which accordingly raises the probability of using common, easy-to-use, cheap, and advanced means of communication.

The researcher followed two ways to collect the needed data. First, an online survey; posting an announcement within the student Facebook group informing them about the questionnaire to be filled; such questionnaire was uploaded on the instructor's Website as a soft copy. Second, a hard copy was disseminated to almost all the students who attended the first-day exam and who did not fill-in the online questionnaire. The statistical software package SPSS Version 19 was used to analyze the collected data. In addition, One-Way ANOVA was used to address possible differences in students' responses (regarding the second section of questionnaire) due to gender and age at a $5 \%$ level of significance.

\section{Results and Discussion}

42 of respondents (33\%) were male, and $85(67 \%)$ were female, 99 of respondents were less than 25 years old, 19 were between the ages of 25 - less than 30 years, 5 respondents between 30 - less than 35, 4 between 35 - less than 40 years old.

\section{Insert Table 1 here}

As shown in Table 1, 50\% of the respondents use Facebook daily, $7 \%$ use it weekly, and $42.5 \%$ use it irregularly. These findings address RQ1, and researcher considers them as promising.

To answer RQ2; results reveal that the majority of students (67\%) use Facebook for contacting their friends, as the researcher expected; $42 \%$ for educational purpose; $29 \%$ for political purpose; $28 \%$ for entertainment; and $20 \%$ for other purposes.

\section{Insert Table 2 here}

As shown in Table 2 shown, in a descriptive way, there are many different aspects of using Facebook in educational context. Approximately $85 \%$ of the students use Facebook to be in touch with their teachers, the current researcher considers that to be an encouraging result in terms of the using Facebook in the Egyptian educational filed. $73.2 \%$ of the students use Facebook for expressing their own opinion regarding the administration policies, faculty strategy, thus, the college administration would use students' opinions as a feedback that would help the institution to make progress in the educational service.

More than $75 \%$ of student use Facebook to contact the faculty administration, which would enhance the previous result. More than $60 \%$ of students considered Facebook supporting college to create a suitable virtual educational environment. Around $78 \%$ of students stated that using the Facebook group raises the probability of using Facebook in the educational context. More than $70 \%$ of students are convinced that they have added value when using Facebook in the educational context, which is considered as the answer of RQ3. The recent findings shown in Table A.2 refer to the applicability of Facebook in the educational domain, and imply that Facebook would be successful in this context as it is in the social one. Although, $70 \%$ of students are not convinced that the present collegial culture supports using Facebook for educational purpose, which means it is a weakness that would encounter the potential success of Facebook in the academic setting.

In terms of answering RQ4, the means of students' satisfaction regarding their connection with teachers, colleagues, and administration, are $3.03 ; 3.89$; and 2.77 , respectively. Totally, current researcher finds these 
means logical, and expected. Although, researcher argues that, the former and the latter percentages needed to be increased by using untraditional and effective communication platform as Facebook.

In addition, when students connecting with their teachers, they are not restricted only to the educational conduct, but they exceed to conduct social and political issues; results show that when respondents are connected with their teacher; $81.9 \%$ were using Facebook for educational purpose; $36.2 \%$ for social conduct; $14.2 \%$ for political purpose. Current research argues that, such variety may promote the notion of using Facebook to enhance the relationship between the students (who have different concerns) and their teachers (as an important party in the educational environment).

The study also explored an important finding; that when students were asked to rank the range of Facebook usage for educational purpose within their educational environment to be unacceptable, or acceptable, or excellent, the percentages of their responses were; 39\%; 48.8; 11.8, respectively. Current researcher considers these ratios as encouraging for pushing the educational institution forward to get more advancement in the terms of using Facebook in the academic setting.

Regarding RQ5, it was found that the students' responses did not vary regarding the second section of the questionnaire (Q5-Q16) that reflects different aspects in which students use Facebook in educational environment, except for the issue of how far the Facebook groups enhance its usage for educational purpose; and also for the student evaluation regarding the usage range of Facebook within their educational environment. In addition, almost of the responses did not vary due to the age, there are just two significant differences; one is the issue of using Facebook to connect with teachers, and the other is about the purpose that Facebook is being used for, when students connected with their teachers.

\section{Conclusion and Implications}

Since unreached consensus regarding how to evaluate the effectiveness of SNSs (Attia, et al., 2011), the current research is exploratory; aims at explore the potential role of the Facebook in the Egyptian higher education, as it has done a great job in the Egyptian revolution 2.0. The research based on 127 questionnaires. Around $78 \%$ of students stated that using Facebook group raises the probability of using it in the educational context; $70 \%$ of students are not convinced that the present collegial culture supports using Facebook for educational purpose. In addition, the responses did not vary due the gender and age in terms of the added value they gained when using Facebook for educational purpose. Also they did not vary regarding the issue of satisfaction about the connection with their teachers, colleagues, and administration. Based on the findings, it can be concluded that there is a promising environment to use Facebook in Egyptian academic setting. Generally, that would be supported by many researchers (Bicen \& Cavus, 2011; Grosseck et al., 2011; Roblyer et al., 2010).

The study has many implications; it would get the educational institution to pay more attention about how to increase the level of service quality it provides, based on opening untraditional two-way communication channels; that would enable the institution to get quick feedback from the students (customers), that may be used to operate continuous improvement. In addition, Facebook would facilitate the service provider (institution) initiatives or reply to the customers (students). That would be backed by what Bickart \& Schindler (2001) stated "within consumer communities, discussion participants can obtain product information, learn general information about the activity, and develop relationship with others that share their interest" (p. 32). Also, as National Authority for Quality Assurance \& Accreditation of Education-Egypt (NAQAAE) values the student participation in educational institution as an important requirement of accreditation, such institution would benefit from the current study in which it could use Facebook as a means to facilitate such participation. In return, getting accreditation would enhance the competitive position of the institution in the educational market. In addition, according to the cost benefit analysis, Facebook can be considered an interactive, quick, and cheap tool to gain the previous returns.

\section{Further Studies}

Current research may be considered a pilot study, which would provide awareness to the Egyptian educational institutions to use Facebook in the academic setting. Although, there is a necessity to conduct further studies in this context, that would address the key variables that influencing the acceptance of Facebook as a part of the virtual educational environment, and to uncover the possible cause- and- effect relationship between using Facebook for educational purpose and a set of dependent variables, such as student/customer satisfaction; the educational service quality, service recovery, etc., that based on more advanced analysis. 


\section{Limitation}

Although the current researcher targeted all the graduate students enrolled in the preparatory year for Master degree (academic year 2011-2012), in the Faculty of Commerce, Mansoura University, a few number of students did not receive a hard copy of the questionnaire. That was not intended. This happened because the researcher was distributing questionnaires before students left the exam location, but unfortunately, there was a great variation between the students in terms of the time of finishing the exam, that made confusion, and hence losing a few number of respondents.

\section{References}

Andrew, D., Smock, Nicole, B., Ellison, Cliff Lampe \& Donghee Yvette Wohnb. (2011). Facebook as a toolkit: A uses and gratification approach to unbundling feature use. Computers in Human Behavior, 27, 2322-2329. http://dx.doi.org/10.1016/j.chb.2011.07.011

Anne West, Jane Lewis \& Peter Currie (2009). Students' Facebook 'friends': public and private spheres. Journal of Youth Studies, 12(6), 615-627. http://dx.doi.org/10.1080/13676260902960752

Ashraf M. Attia, Nergis Aziz, Barry Friedman \& Mahdy F. Elhusseiny. (2011). Commentary: The impact of social networking tools on political change in Egypt's "Revolution 2.0". Electronic Commerce Research and Applications, 10, 369-374. http://dx.doi.org/10.1016/j.elerap.2011.05.003

Barbara Bickart \& Robert M. Schindler. (2001). Internet Forums as Influential Sources of Consumer Information. Journal of interactive marketing, 15(3), 31-40.

Basheer A. Al-Alak \& Ahmad Salih Mheidi Alnaser. (2012). Assessing the Relationship Between Higher Education Service Quality Dimensions and Student Satisfaction. Australian Journal of Basic and Applied Sciences, 6(1), 156-164.

Bogdanel Marian Dragut. (2011). Quality management in higher education services. Procedia Social and Behavioral Sciences, 15, 3366-3368. http://dx.doi.org/10.1016/j.sbspro.2011.04.301

Cristian Stefan Craciun. (2010). The quality consulting services management in the university educational system. Procedia Social and Behavioral Sciences, 2, 5586-5589. http://dx.doi.org/10.1016/j.sbspro.2010.03.911

Fred A. J. Korthagen. (2010). Situated learning theory and the pedagogy of teacher education: Towards an integrative view of teacher behavior and teacher learning. Teaching and Teacher Education, 26, 98-106. http://dx.doi.org/10.1016/j.tate.2009.05.001

Gabriela Grosseck, Ramona Bran \& Laurentiu Tiru. (2011). Dear Teacher, What Should I Write on My Wall? A case Study on Academic Uses of Facebook. Procedia Social and Behavioral Science, 15, 1425- 1430. http://dx.doi.org/10.1016/j.sbspro.2011.03.306

Huseyin Bicen \& Nadire Cavus. (2011). Social Network Sites Usage Habits of Undergraduate Students: Case Study of Facebook. Procedia Social and Behavioral Science, 28, 943-947. http://dx.doi.org/10.1016/j.sbspro.2011.11.174

Hüseyin Uzunboylu, Hüseyin Bicen \& Nadire Cavus. (2011). The Efficient Virtual Learning Environment: A Case Study of Web 2.0 Tools and Windows Live Space. Computer \& Education, 56, 720-726. http://dx.doi.org/10.1016/j.compedu.2010.10.014

Jodi Pilgrim \& Christie Bledsoe. (2011). Learning through Facebook: A Potential Tool for Educators. Delta Kappa Gamma Bulletin, 78(1), 38-42.

Jozee Lapierre, Pierre Filiatrault \& Jean Perrien. (1996). Research on Service quality Evaluation: Evolution and Methodological Issues. Journal of Retailing and Consumer Services, 3(2), 91-98.

M.D. Roblyer, Michelle McDaniel, Marsena Webb, James Herman \& James Vince Witty. (2010). Findings on Facebook in higher education: A comparison of college faculty and student uses and perceptions of social networking sites. Internet and Higher Education, 13, 134-140. http://dx.doi.org/10.1016/j.iheduc.2010.03.002

Muhammad K. Kabilan, Norlida Ahmad \& Mohamad J. Z. Abidin. (2010). Facebook: An online environment for learning of English in institutions of higher education? Internet and Higher Education, 13, 179-187. http://dx.doi.org/10.1016/j.iheduc.2010.07.003

Nazan Dogruer, Ipek Menevis \& Ramadan Eyyam. (2011). What Is the Motivation for Using Facebook? Procedia Social and Behavioral Science, 15, 2642-2646. http://dx.doi.org/10.1016/j.sbspro.2011.04.162 
Nelu Cîrneanu, Mihai Chiriță \& Adelina Cîrneanu. (2009). THE Quality of the Educational Services Offered by the Military Organization. Revista Academiei Fortelor Terestre, 14(4), 7-12.

Nicki Dabner. (2012). Breaking Ground' in the use of social media: A case study of a university earthquake response to inform educational design with Facebook. Internet and Higher Education, 15(1), 69-78. http://dx.doi.org/10.1016/j.iheduc.2011.06.001

Noelle, J., Hum, Perrin, E., Chamberlin, Brittany, L., Hambright, Anne, C., Portwood, Amanda, C. Schat \& Jennifer, L. Bevan. (2011). A picture is worth a thousand words: A content analysis of Facebook profile photographs. Computers in Human Behavior, 27, 1828-1833. http://dx.doi.org/10.1016/j.chb.2011.04.003

William, P. Smith \& Deborah, L. Kidder. (2010). You've been tagged! (Then again, maybe not): Employers and Facebook. Business Horizons, 53, 491-499. http://dx.doi.org/10.1016/j.bushor.2010.04.004

Note

Note 1. The current study questionnaire relied on (Grosseck, Bran, \& Tiru, 2011; Kabilan, Ahmad, \& Abidin, 2010).

Table 1 . The introductory questions

\begin{tabular}{|c|c|c|c|c|c|c|c|c|c|c|}
\hline I use & \multicolumn{4}{|c|}{ Daily } & \multicolumn{3}{|c|}{ Weekly } & \multicolumn{3}{|c|}{ non-regular } \\
\hline & \multicolumn{2}{|c|}{ Frequency } & \multicolumn{2}{|c|}{ Percent } & \multicolumn{2}{|c|}{ Frequency } & Percent & \multicolumn{2}{|c|}{ Frequency } & Percent \\
\hline & \multicolumn{2}{|c|}{64} & \multicolumn{2}{|c|}{50.4} & \multicolumn{2}{|l|}{9} & 7.1 & \multicolumn{2}{|c|}{54} & 42.5 \\
\hline \multirow[t]{3}{*}{$\begin{array}{l}\text { I use } \\
\text { Facebook for }\end{array}$} & \multicolumn{2}{|c|}{ Entertainment } & \multicolumn{2}{|c|}{$\begin{array}{l}\text { Contacting my } \\
\text { friends }\end{array}$} & \multicolumn{2}{|c|}{ Educational Purpose } & \multicolumn{2}{|c|}{$\begin{array}{l}\text { for Political } \\
\text { Purpose }\end{array}$} & \multicolumn{2}{|c|}{$\begin{array}{c}\text { For other different } \\
\text { purposes }\end{array}$} \\
\hline & Freq & Percent & Freq & Percent & Freq & Percent & Freq & Percent & Freq & Percent \\
\hline & 35 & $27.6 \%$ & 85 & $66.9 \%$ & 53 & $41.7 \%$ & 37 & $29.1 \%$ & 26 & $20.5 \%$ \\
\hline \multirow{3}{*}{$\begin{array}{l}\text { I prefer using } \\
\text { Facebook in }\end{array}$} & \multicolumn{4}{|c|}{ Arabic Version } & \multicolumn{3}{|c|}{ English Version } & \multicolumn{3}{|c|}{ No Response } \\
\hline & \multicolumn{2}{|c|}{ Frequency } & \multicolumn{2}{|c|}{ Percent } & Frequency & \multicolumn{2}{|c|}{ Percent } & \multicolumn{2}{|c|}{ Frequency } & Percent \\
\hline & \multicolumn{2}{|c|}{48} & \multicolumn{2}{|c|}{$37.8 \%$} & 76 & \multicolumn{2}{|c|}{$59.8 \%$} & \multicolumn{2}{|l|}{$3 \mathrm{~S}$} & $2.4 \%$ \\
\hline
\end{tabular}


Table 2. Different aspects of using Facebook in academic setting

\begin{tabular}{|l|c|c|c|c|c|c|c|}
\hline & 1 & 2 & 3 & 4 & 5 & Mean & SD \\
\hline $\begin{array}{l}\text { I use Facebook to be in touch with } \\
\text { my teachers }\end{array}$ & $2.4 \%$ & $0.8 \%$ & $11 \%$ & 35.4 & 48.8 & 4.23 & 1.03 \\
\hline $\begin{array}{l}\text { I use Facebook for expressing my } \\
\text { own opinion regarding the } \\
\text { administration policies, faculty } \\
\text { strategy, etc. }\end{array}$ & $3.9 \%$ & $3.1 \%$ & $18.1 \%$ & $36.2 \%$ & $37 \%$ & 3.94 & 1.14 \\
\hline $\begin{array}{l}\text { I use Facebook to contact the faculty } \\
\text { administration }\end{array}$ & $3.9 \%$ & $3.1 \%$ & $15.7 \%$ & $40.9 \%$ & $34.6 \%$ & 3.94 & 1.12 \\
\hline $\begin{array}{l}\text { Facebook supports creating a } \\
\text { suitable virtual educational } \\
\text { environment }\end{array}$ & $1.6 \%$ & $5.5 \%$ & $29.9 \%$ & $32.3 \%$ & $28.3 \%$ & 3.73 & 1.12 \\
\hline $\begin{array}{l}\text { Facebook groups raise the chance of } \\
\text { using Facebook in the educational } \\
\text { context }\end{array}$ & $2.4 \%$ & $1.6 \%$ & $16.5 \%$ & $35.4 \%$ & $42.5 \%$ & 4.09 & 1.06 \\
\hline $\begin{array}{l}\text { I get an added value when using } \\
\text { Facebook in the educational context }\end{array}$ & $0.8 \%$ & $7.9 \%$ & $19.7 \%$ & $37 \%$ & $33.1 \%$ & 3.89 & 1.08 \\
\hline $\begin{array}{l}\text { The present organizational culture } \\
\text { supports using Facebook in the } \\
\text { educational context }\end{array}$ & $14.2 \%$ & $18.1 \%$ & $36.2 \%$ & $21.3 \%$ & $8.7 \%$ & 2.87 & 1.20 \\
\hline $\begin{array}{l}\text { Totally, I'm satisfied with the range } \\
\text { of connection between me and my } \\
\text { teachers }\end{array}$ & $12.6 \%$ & $18.1 \%$ & $29.9 \%$ & $24.4 \%$ & $13.4 \%$ & 3.03 & 1.27 \\
\hline $\begin{array}{l}\text { Totally, I'm satisfied with the range } \\
\text { of connection between me and my } \\
\text { colleagues }\end{array}$ & $1.6 \%$ & $7.1 \%$ & $16.5 \%$ & $42.5 \%$ & $30.7 \%$ & 3.89 & 1.07 \\
\hline $\begin{array}{l}\text { Totally, I'm satisfied with the } \\
\text { range of connection between me and } \\
\text { the administration }\end{array}$ & $20.5 \%$ & $15 \%$ & $35.4 \%$ & $17.3 \%$ & $10.2 \%$ & 2.77 & 1.29 \\
\hline
\end{tabular}

